\title{
Communication Technology for Student With Visual Impairments: A Case Study of Smartphone
}

\author{
$1^{\mathrm{st}}$ Siska Mardiana \\ Faculty of Communication Science \\ Universitas Padjadjaran \\ Bandung Indonesia \\ Departement of Communication Science \\ Universitas Serang Raya \\ Serang Indonesia \\ siska17003@mail.unpad.ac.id \\ $3^{\text {rd }}$ Dadang Sugiana \\ Faculty of Communication Science \\ Universitas Padjadjaran \\ Bandung Indonesia \\ dadang.sugiana@unpad.ac.id
}

\author{
$2^{\text {nd }}$ Jenny Ratna Suminar \\ Faculty of Communication Science \\ Universitas Padjadjaran \\ Bandung Indonesia \\ jenny.suminar@unpad.ac.id \\ $4^{\text {th }}$ Suwatno \\ School of Post Graduate Studies \\ Universitas Pendidikan Indonesia \\ Bandung Indonesia \\ suwatno@upi.edu
}

\begin{abstract}
Smartphone in general can be used and accessed visually, but it turns out students with visual impairments can also use it with a screen reader, and this smartphone is also used in learning. The changing paradigm of teaching and learning in the world of education, provides space for students to be more active in the learning process. The purpose of this study was to find out how to use smartphones on students with visual impairments. The method used is a case study method with a qualitative approach. The informants in this study were five SLBN A students from Bandung, Indonesia. Data obtained by in-depth interviews, observations, and documentation studies, then analyzed and tested the validity of the data with triangulation. The results showed smartphone in daily activities in learning is used to find information related to the material, do homework, take notes and record when studying in class, interact through social media and create creative content such as YouTube content. The activities carried out using smartphones ultimately help them achieve learning goals, because they can more actively look for sources of information in learning.
\end{abstract}

Keywords - smartphone, students with visual impairments, communication technology

\section{INTRODUCTION}

Communications technologies have been developing and playing an essential role in various aspects of life, one of which is the education sector [1]. The various communications technologies have been developed in such a way that they are applicable not only to non-disabled persons but also to those who have vision impairment. One of such technologies is the smartphone. Smartphones are technological devices which offer satisfaction to users with features such as those applications for listening to music, watching films, chatting on social media, conducting trade transactions, seeking information, to name just a few [2][3].
Smartphones are commonly used and accessed by visual means, but they can also be used by children with vision impairment with sound assistance through the smartphones' settings [4]. To make such settings, users should go to the menu Settings, Accessibility, Vision, and Voice Assistant, then hit OK. The smartphone visually impaired children hold has voice outputs to help them access it. This is made possible by the screen reader that comes with the phone. Screen reader can be accessed with the TalkBack application for Android phones or the VoiceOver application for iPhones [3].

The interaction of a visually impaired child in lessons may take place not only in a face-to-face setting but also mediated with communications technology like smartphone [5]. Almost all children with vision impairment own and take a smartphone to the school. At school, smartphone is usually used during break time or when there is no class, but for some subjects, smartphone is also used during the class hours for purposes such as recording and taking notes as it is faster than writing in Braille, but such smartphone use during class must be in accordance with the teacher's instruction.

We encounter such phenomenon of smartphone use in students of State Special Needs School A of Bandung City. This school is the largest center for education and training in Indonesia and is the oldest special needs school in Southeast Asia, established in 1901. It organizes education for students with vision impairment at elementary school, junior high school, and senior high school levels. The visually impaired students attending this school are those with total blindness, low vision, or multiple disabilities with visual impairment (MDVI). Students with total blindness are those with total vision impairment and are incapable of sight at all. Students with low vision still have vision ability to varying degrees. Meanwhile, students with MDVI are those who in addition to have vision impairment also experience other disorders such as autism or spine disorders. Smartphone use at school is 
common among students with total blindness or low vision, but among students with MDVI it seems to be rare.

A previous joint study by Facebook and Cornell University entitled How Blind People Interact with Visual Content on Social Networking Services (2016) revealed that persons with disability, including those with visual impairment, try to use technology just like persons in common, for example, for engaging in social media.

This study was conducted by in-depth interview with 11 individuals and by survey on 60 visually impaired respondents. The results show that all respondents used Facebook, 60 percent used Twitter, and 22 percent used Instagram. Besides, the results also show that persons with visual impairment also posted photographs and videos and updated status but they did so in a lower intensity than nonvisually-impaired peers. When using smartphone, visually impaired persons use extra features like screen reader and screen magnifiers. One of the screen readers most popular is Apple's VoiceOver. With VoiceOver, visually impaired smartphone users conduct virtually all activities on the device, for example, for using WhatsApp. All the buttons on WhatsApp and even the text messages contained are read out by VoiceOver (https://tirto.id/membuka-dan-mendengardunia-dengan-aplikasi-disabilitas-cFH6).

The changing paradigm of teaching and learning in the education sphere gives room to students to be increasingly active in the learning process [6]. Smartphone use becomes of interest to students with visual impairment thanks to the Internet connection [7]. Their subscribing to the Internet mostly is driven by the intention to keep abreast of the latest news via search engine Google and to interact socially with peers via platforms such as WhatsApp, YouTube, and Facebook [8].

Education today has shifted from traditional, print-based teaching and learning methods to the digital format [1]. Visually impaired children find it easier to write, read, and acquire learning materials via smartphone. Additionally, with the growing quantity of web-based learning sources now the Internet has made available an access to various disciplines as well as wide-ranging learning opportunities. Children with visual impairments now are enabled to find learning materials independently via the Internet under the teacher's instruction. With that background in mind, we focused our research on how the smartphone communications technology is used by students with visual impairment during learning.

\section{MethodS}

This research employed a qualitative approach and a case study method. A case study refers to an investigation of a case in real life in the contemporary context or setting [9]. It is a method used to reveal a phenomenon along with the context, in this case the phenomenon of smartphone communications technology use in visually impaired students' interactions.

Serving as informants in this research were five students of State Special Needs School A of Bandung City, Indonesia, who were enrolled by purposive sampling technique. Data were collected by in-depth interview, observation, and document study and then subjected to analysis, data validity testing, and triangulation.

\section{RESULTS AND DISCUSSION}

Smartphone is used by students with visual impairment to assist in their completion of assignments from the teacher to find particular materials via search engine Google to be discussed together. During the learning process at school, students not only receive learning materials from the teacher but also are demanded to actively seek materials on their own by the Internet technology. For instance, during Indonesian Language class, the teacher instructs the students to find an example of a piece of poetry over the Internet via smartphone to be discussed and then assigns them to compose a poetry work of their own, them sent via whatsapp. WhatsApp use on smartphone by these students with visual impairments is assisted by typing directly, the voice note, or text-to-speech feature.

In addition, on the subject of computer implications, at certain class hours the teacher gives assignments through WhatsApp, assignments are sent in the form of words, then students also collect their assignments through WhatsApp again in the form of words, pdf, txt or voice notes, or some are collect tasks by sending an email. Here the teacher gives students freedom to encourage students to be more active in learning.

Figure 1 shows an example of a task sent via whatsapp on a smartphone device. Some questions via WhatsApp that become assignments to be done by students are students asked to tell the benefits of what they get with the computer, then what is the negative influence of information technology or social media, then students are asked to collect at the specified time and date. In this figure you can also see replies from students who sent answers to the assignment, which were in the form of txt files, also in the form of voice note recordings.

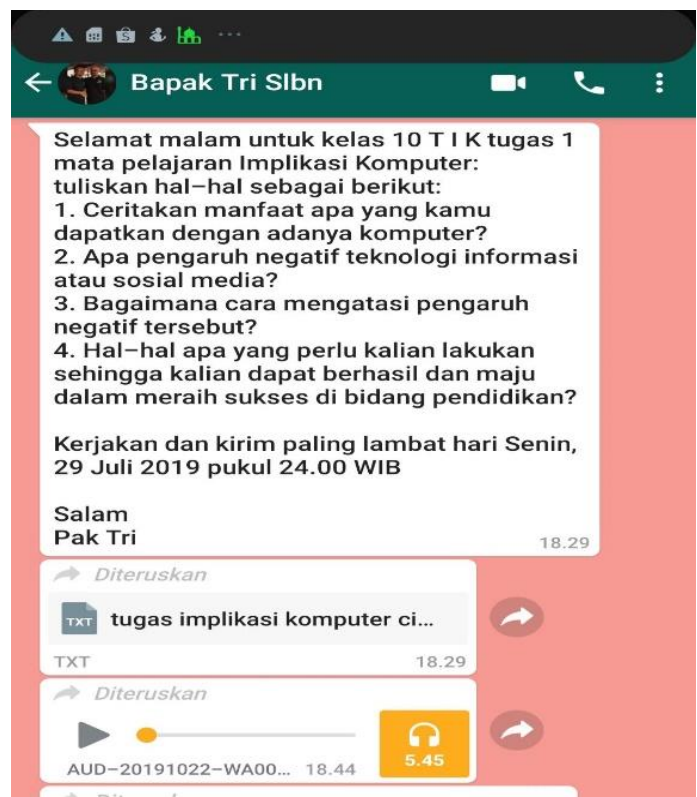

Fig. 1. Homework via whatsapp

Also on this subject, the teacher who taught held a distance learning by inviting a speaker of a college student with visual impairment at an University in Tangerang, Indonesia, who understood and was an expert on technology, especially technology for those who have visual impairments. This learning takes place interactively using smartphone devices and speakers. Furthermore, after the lesson session, as a form of evaluation, students are asked to express their opinions 
about the learning session with this teleconference via whatsapp on a smartphone.

Smartphone is also used for note-taking during the learning as it is easier to take a note on smartphone than writing in Braille, which would demand accuracy and skill. Students use smartphone for note-taking and recording purposes when studying in the classroom and in other activities which require note-taking. Although they are still taught Braille characters for them to read and write, smartphone is also used as an aid.

They can use smartphones because of the help of voice that reads or describes all the activities they do while using a smartphone, so students with visual impairments are also accustomed to carrying earphones or headsets so that when they hear the sound from a smartphone they can focus and not disturb others. As one of the students did when observing the researcher, it was seen on his desk that there were smartphones, papers and tools for writing braille. He was working on the task of the teacher to find information through google search, then he copied the information into Braille writing.This is as presented in Fig 2.

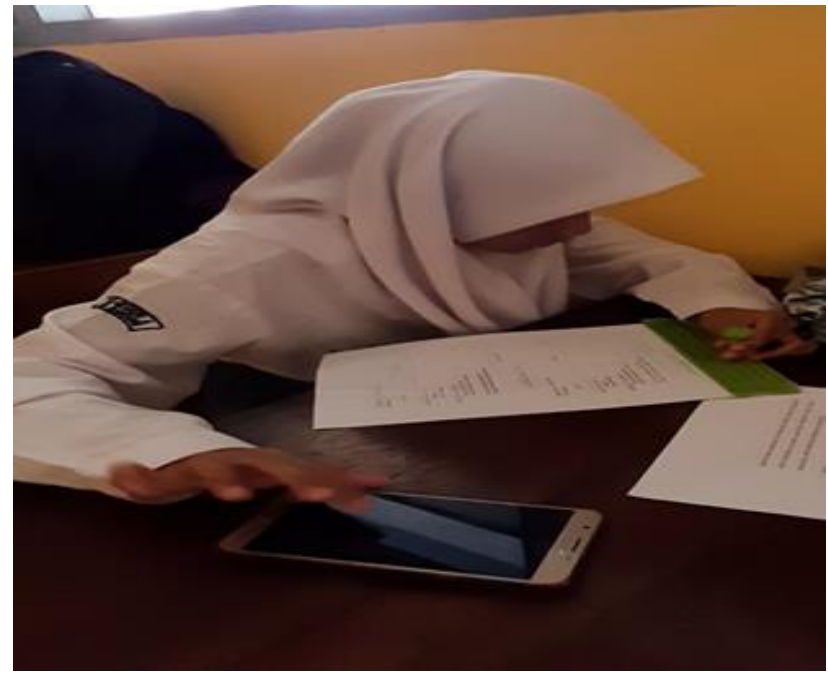

Fig. 2. Students with vision impairment are using smartphone to find materials on the Internet as assigned by the teacher

\section{A student in an interview explained the following:}

"I take my smartphone to the school because sometimes during the lesson hours the teacher gives an assignment that must be done with smartphone. For instance, during the Math lesson, the teacher would assign that the students find out through Google what is meant by three-dimensional and twodimensional figures. Besides, it is easier to take a note on smartphone. When there are some important points I must note fast, I find it preferable to use smartphone as it is simpler. Noting in Braille won't allow fast note-taking. But it is still a must for me to be able to read and write in Braille because this alphabet is used in quizzes."

Not only is it used to assist in finding information or completing assignments, smartphone is also used to interact with others, for example, through social media. Some of the social media the students use are WhatsApp, Facebook, and YouTube. Through WhatsApp, for example, they can communicate with friends who join the same group as theirs. Some students even join WhatsApp groups beyond their school environments like one of IT Center for the Blind dedicated for the community with vision impairments and interest in ICT.

This is as explained by an informant below:

"I use smartphone for accessing social media like WhatsApp, Facebook, and YouTube. WhatsApp, for instance, allows me to engage in a group chat with my friends, ask about assignments, or discuss information and communications technology or simply anything. I used to actively manage a blog, but now, I move to YouTube and create tutorial videos so I can share my knowledge. There's this saying that it is encouraged for one to share knowledge with others. Not only tutorial videos, I also upload videos of plays on YouTube too."

Smartphone-aided communication can be conducted with a variety of applications, one of which is TeamTalk, an application for building worldwide blind solidarity. This application can be acquired through Play Store. It is useful for learning, communication, and sharing. Unlike WhatsApp which uses voice note to which responses require some time, TeamTalk is askin to teleconference and thus it is interactive in nature. TeamTalk is composed of multiple channels and we can decide on joining which channel to our need and desire. Through TeamTalk students with vision impairment can interact and gain information, thus benefiting their learning. This is as presented in Fig 2.

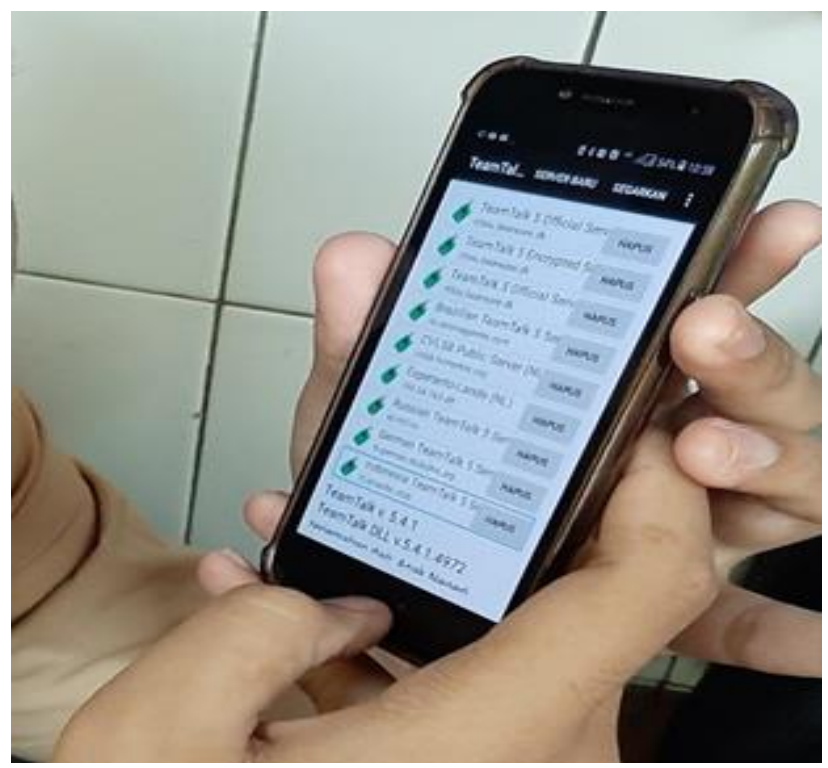

Fig. 3. TeamTalk Application

Based on the research results, smartphone is applicable to students with vision impairment in learning process for communicating and interacting with peers and teachers thanks to the screen reader feature available and the various applications they can obtain from Play Store if they use Android-based smartphone or App Store if they use iPhone. Smartphone in daily learning activities is used for finding information, completing home assignments, note taking and recording in the classroom, interacting over social media, and making creative content such as YouTube content. Smartphone use ultimately helps them achieve their learning goals as it enables them to actively search for lesson-related information. This is as can be seen in the figure 4 . 


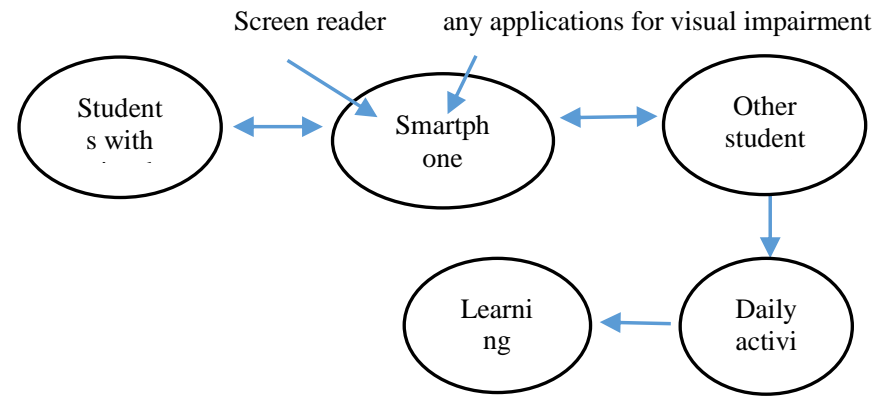

Fig. 4. Smartphone usage for students with visual impairment in learning

Advances in communications technology have brought changes to the education sphere where learning is conducted not only face-to-face in classroom settings but also aided with media like smartphone outside classroom and lesson hours [6]. Education today has shifted from traditional, print-based teaching and learning methods to the digital format [1][10]. Technology has also altered students' learning paradigm into using digital technology power and the Internet to achieve educational success [8]. Even students with vision impairment are now enabled to keep up with current developments through using digital technology in many ways, including using smartphone with screen reader assistance and a multitude of applications in the learning process.

\section{CONCLUSION}

Advance in communication technology have given birth to many new forms of media in computer-based communication including smartphones, and this technology is not only for those who are normal but also for children with visual impairments. Smartphones are generally accessed visually, but it turns out that with the help of a screen reader it is very helpful for students with visual impairments to use a smartphone both to help in the learning process as well as to interact with their environment, such as used in recording subject matter, because it is easier than writing in braille which requires precision and skill. They use this smartphone to take notes and record while studying in class and in other activities that require notes, in addition to doing school work through information search on Google, and smartphones are also used to interact through social media.

\section{REFERENCES}

[1] J. R. Suminar and M. Trisyani, "Online Course: Media Empowering in Education Process,” Procedia - Soc. Behav. Sci., vol. 67, no. November 2011, pp. 203-207, 2012.

[2] V. Rotondi, L. Stanca, and M. Tomasuolo, "Connecting alone: Smartphone use, quality of social interactions and well-being," J. Econ. Psychol., vol. 63, pp. 17-26, 2017.

[3] T. Chanjaraspong, "Acceptance factors for the use of video call via smartphone by blind people,” Kasetsart J. Soc. Sci., vol. 38, no. 1, pp. 81-87, 2017.

[4] N. Sultan, K. Siddiq, T. Rashid, and M. Farooque, "Evaluation of Smart Phone Applications Accessibility for Blind Users," Int. J. Comput. Appl., vol. 127, no. 3, pp. 0975-8887, 2015.

[5] R. J. Dwyer, K. Kushlev, and E. W. Dunn, "Smartphone use undermines enjoyment of face-to-face social interactions," J. Exp. Soc. Psychol., vol. 78, no. October 2017, pp. 233-239, 2018.

[6] F. Bouarab-Dahmani and R. Tahi, "New Horizons on Education Inspired by Information and Communication Technologies," Procedia - Soc. Behav. Sci., vol. 174, pp. 602-608, 2015.

[7] L. Hakobyan, J. Lumsden, D. O’Sullivan, and H. Bartlett, "Mobile assistive technologies for the visually impaired," Surv. Ophthalmol. vol. 58, no. 6, pp. 513-528, 2013.
[8] N. Dogruer, R. Eyyam, and I. Menevis, "The use of the internet for educational purposes," Procedia - Soc. Behav. Sci., vol. 28, pp. 606$611,2011$.

[9] Yin, R. K. (2009). Case study research: Design and methods (4th Ed.). Thousand Oaks, CA: Sage. 2013. 